\title{
Porokeratosis: Two Faces, One Family
}

\author{
S. Lembo L. Panariello L. Nugnes C. Lembo F. Alaya
}

Department of Dermatology, University Federico II, Naples, Italy

\section{Key Words}

Giant porokeratosis - Linear porokeratosis · Cornoid lamella · Abnormal clone of keratinocytes

\begin{abstract}
Porokeratosis is a disorder of keratinisation whose pathogenesis is yet unclear. It has been postulated that it results from the proliferation of an abnormal clone of keratinocytes, triggered by several factors, such as immunosuppression or prolonged ultraviolet exposure. Various clinical forms are recognized whose common denominator is a keratotic ring surrounding a central zone of atrophy. The histological hallmark is the cornoid lamella, a thin column of hyperproliferative abnormal keratinocytes. We describe two cases of porokeratosis. A 67-year-old woman with an erythematous purplish round plaque surrounded by a keratotic border that had appeared 6 years previously on the left sural region was diagnosed as 'giant' porokeratosis. A 49-year-old man presented with small papules coalescent in an erythematous oval plaque on the lateral side of the left foot consistent with linear porokeratosis.
\end{abstract}

Porokeratosis is a benign disorder of keratinisation whose pathogenesis is yet unclear. The histological hallmark is the cornoid lamella, a thin column of hyperproliferative parakeratotic keratinocytes. Several risk factors of porokeratosis have been identified including genetic inheritance, ultraviolet radiation, and immunosuppression. We describe two patients with porokeratosis; in both cases the clinical suspicion was confirmed by histological examination.

\section{Patient 1}

A 67-year-old Caucasian woman presented with a lesion on her left sural region which consisted of an erythematous purplish round plaque, surrounded by a 'sharp' keratotic border, measuring about $3.5 \mathrm{~cm}$ in diameter (fig. 1). The lesion had appeared 6 years earlier and was occasionally slightly itching. Topical treatment with corticosteroids or keratolytic agents did not lead to any improvement. The patient had brown hair and was classified as skin phototype 3 according to Fitzpatrick's classification [1]. She had been suffering from type 2 diabetes for 12 years and was on treatment with oral hypoglycemic agents; moreover, she was paraplegic as a consequence of poliomyelitis. At clinical examination neither photodamage nor any other dermopathy were assessed. The clinical diagnosis of 'giant' porokeratosis was strongly suggested by the typical palpable sharp border. Multislice histological 


\begin{tabular}{l|l|l|l} 
Case Reports $h$ & Case Rep Dermatol 2009;1:52-55 & Published online: October 2, 2009 & $\begin{array}{l}\text { @ 2009 S. Karger AG, Basel } \\
\text { ISSN 1662-6567 } \\
\text { Wwww.karger.com/cde }\end{array}$ \\
\hline
\end{tabular}

examination confirmed the clinical suspicion [2]. The epidermis was hyperplastic, hyperkeratotic and showed a typical column of parakeratosis corresponding to the cornoid lamella; no granular layer was seen beneath the parakeratotic column. The papillary dermis showed an unspecific, mild lymphocytic infiltrate, in addition to dilated capillaries and incontinentia pigmenti. Treatment consisted of oral tretinoin $(0.5 \mathrm{mg} / \mathrm{kg} /$ day for 2 months $)$. At the end of the treatment the lesion slightly improved; therefore, the patient decided to stop the therapy, since the lesion had always been almost asymptomatic.

\section{Patient 2}

A 49-year-old man presented with an oval plaque on the latero-dorsal side of the left foot (fig. 2) that had probably appeared during childhood. Because of an eroded papula which had appeared within the lesion several weeks earlier, the general practitioner had hypothesized a squamous cell carcinoma, and therefore the patient had been referred to our clinic. At first observation, the characteristic ridge-like border oriented towards the diagnosis of porokeratotic eccrine ostial and dermal duct naevus.

Histopathological examination showed the cornoid lamella, but the pathognomonic dermal eccrine duct beneath the parakeratotic column was not detected [3]. In accordance with the dermopathology team a diagnosis of linear porokeratosis was made. The plaque probably derived from the confluence of discrete papules in the final 'geographic' appearance. The eroded area included in the plaque was diagnosed as a benign and probably trauma-induced lesion and treated with a $8 \%$ zinc oxide emulsion. Its complete regression within about 3 months confirmed such a diagnosis. At four-year follow-up no recurrence was found.

\section{Comments}

Porokeratosis is a disorder of keratinisation first described by Mibelli in 1893 [4]. Five clinical variants of porokeratosis are recognized: classic porokeratosis of Mibelli, disseminated superficial actinic porokeratosis, porokeratosis palmaris et plantaris disseminata, linear porokeratosis, and punctate porokeratosis. Lesions are characterized by an atrophic centre and a keratotic ridge-like border. The histological hallmark is the cornoid lamella, a thin column of hyperproliferative parakeratotic keratinocytes. The pathogenesis is unclear; it has been postulated that it results from proliferation of an abnormal clone of keratinocytes. Several risk factors of porokeratosis have been identified, including genetic inheritance, ultraviolet radiation, and immunosuppression.

The lesions of porokeratosis characterized by a keratotic rim tend to expand slowly in a centrifugal fashion, leaving in their wake a zone of atrophy. At one moment in time, the lesions stop expanding and tend to last. A malignancy can rarely occur at the lesion site; in order of frequency, squamous cell carcinoma, Bowen's disease or basal cell carcinoma have been described in the literature [5]. It is controversial whether this occurrence is just a coincidence of photo-induced, immunosuppression-induced damage or the expression of a familial genetic trait.

Multiple empiric therapies such as topical 5-fluorouracil, retinoids or salicylates have been proposed. Cryotherapy or surgical excision may also be performed. An accurate clinical follow-up is necessary in any case. 
Fig. 1. Erythematous purplish round plaque surrounded by a 'sharp' keratotic border: giant porokeratosis, clinical and histopathological picture.

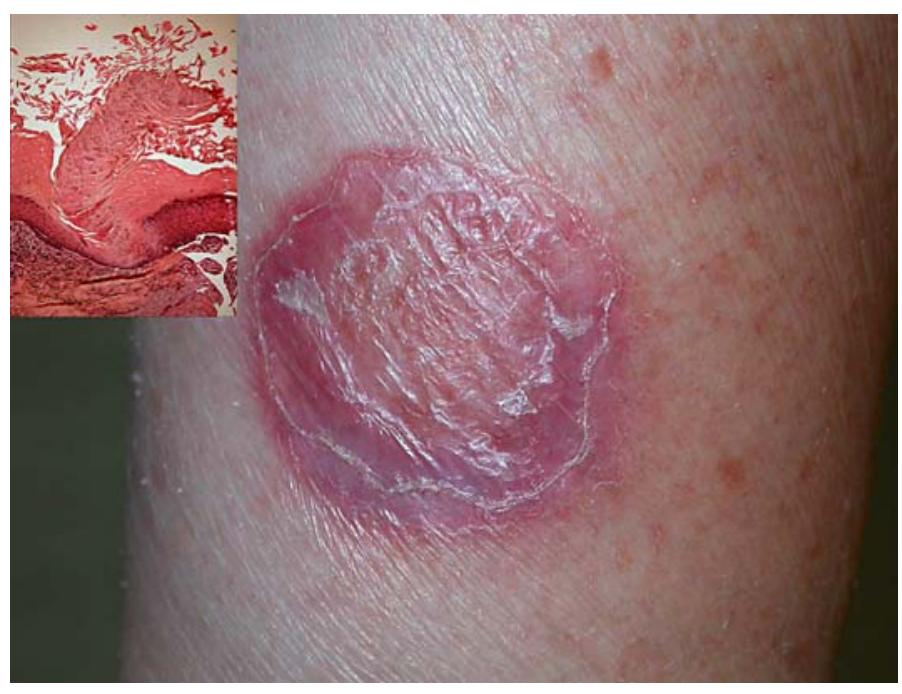

Fig. 2. Oval plaque with ridge-like border: linear porokeratosis, clinical and histopathological picture.

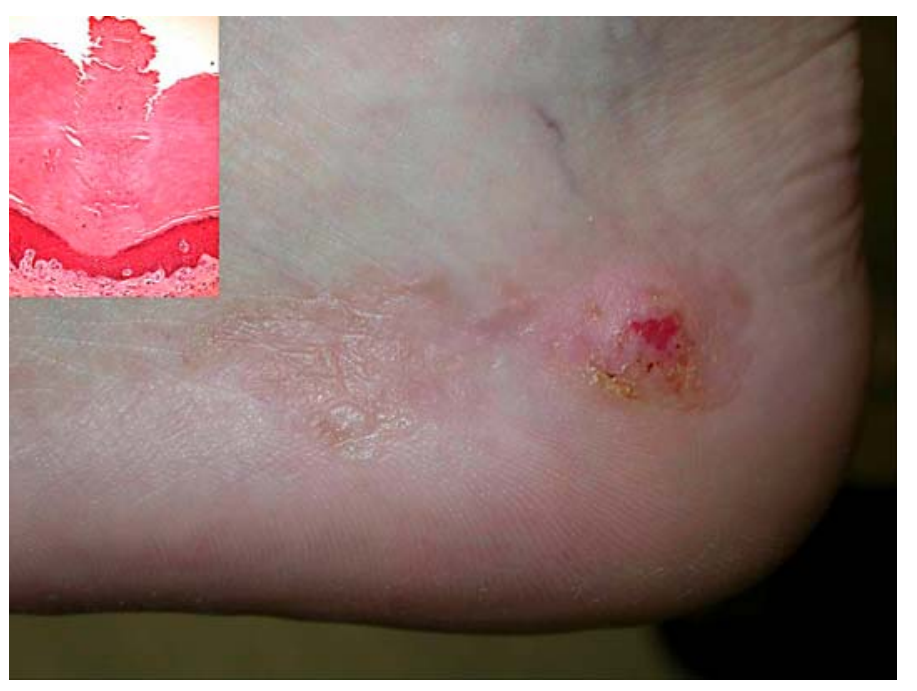




\section{References}

1 Fitzpatrick TB: The validity and practicability of sun-reactive skin types I through VI. Arch Dermatol 1988;124:869-871.

2 Sassmannshausen J, Bogomilsky J, Chaffins M: Porokeratotic eccrine ostial and dermal duct nevus: a case report and review of the literature. J Am Acad Dermatol 2000;43:364-367.

-3 Otani Y, Katagiri K, Takeuchi Y, et al: A case of giant porokeratosis with vestiges of a cornoid lamella. J Dermatol 2005;32:894-898.

4 Mibelli V: Contributo allo studio della ipercheratosi dei canali sudoriferi (porokeratosi). G It Mal Vener Pelle 1893;28:313-355.

5 Maubec E, Duvillard P, Margulis A, et al: Common skin cancers in porokeratosis. Br J Dermatol 2005;152:1389-1391. 